\title{
Quantificação Espectrofotométrica de Flavonóides em Rabanete (Raphanus Sativus)
}

Rejane D. P. Mota, Talita L. C. de Castro, Tatiana de Oliveira Zuppa \& Eliane V. Rosa

Tendo em vista o baixo consumo do espécime vegetal rabanete (Raphanus sativus) e a baixa quantidade de publicações relacionadas a análises de fitoquímicos do mesmo, este trabalho teve como foco a pesquisa da quantificarção de flavonóides, componente bioativo com função antioxidante, anti-cancerígena, anti-inflamatório e agente preventivo de doenças cardiovasculares. Através das análises efetuadas confirmou-se a presença deste grupo de compostos fitoquímicos evidenciando a importância do consumo deste alimento.

Palavras-chave: Flavonóides, Rabanete, Alimentos.

In view of the low consumption of the vegetal specimen radish (Raphanus sativus) and low the amount of related publications the analyses of phytochemicals of the same, this work had as focus the research of the quantification of flavonoids, bioactive component with function against inflammation and against rust and against cancerigen function and agent preventive of cardiovascular illnesses. Through the effected analyses it was confirmed presence of this group of phytochemicals composites evidencing the importance of the consumption of this food.

Key words: Flavonoids, Radish, Foods. 


\section{Introdução}

Definidos como produtos, os alimentos funcionais contêm em sua composição alguma substância biologicamente ativa, que ao ser adicionada a uma dieta usual, desencadeia processos metabólicos ou fisiológicos, resultando em redução do risco de doenças e manutenção da saúde ${ }^{1}$. Nesse sentido, devem fazer parte da alimentação usual e proporcionar efeitos positivos, obtidos com quantidades não tóxicas e que exerçam tais efeitos mesmo após a suspensão da ingestão e que não se destinem a tratar ou curar doenças, estando seu papel ligado à redução do risco de contrair doenças².

Os fitoquímicos são substâncias encontradas em frutas e verduras que podem ser ingeridas diariamente em determinadas quantidades e mostram potencial para modificar o metabolismo humano de maneira favorável à prevenção do câncer e de outras doenças degenerativas ${ }^{3}$.

As flavonas, flavanonas, flavanóis, catequinas e antocianinas formam o grupo dos flavonóides. Protegem contra a oxidação do LDL-colesterol através da redução de radicais livres, quelação de íons metálicos e regeneração de alfa-tocoferol; atuam também contra radicais livres, alergias, inflamações, úlceras, virose, tumores e hepatotoxinas; na inibição da agregação plaquetária, reduzindo as cardiopatias e tromboses e a síntese de estrógeno $0^{4}$.

Os flavonóides compõem uma ampla classe de substâncias de origem natural, cuja síntese não ocorre na espécie humana ${ }^{5}$, sendo compostos denominados metabólitos secundários, produzidos pelo organismo das plantas em diferentes concentrações, de acordo com fatores fisiológicos e ambientais. Muitos trabalhos demonstraram que há um aumento quantitativo de flavonóides em órgãos expostos à luz, em comparação com aqueles que estão à sombra ${ }^{6,7}$.

Apesar do termo "flavonóide" derivar do latim flavus, que significa amarelo, observa-se que os grupos flavonóis e flavonas são incolores e que a classe das antocianinas possuem substâncias que variam no seu espectro de coloração do verde ao azul ${ }^{8}$. Destacam-se, dentre outros, os seguintes efeitos dos flavonóides sobre os sistemas biológicos: capacidade antioxidativa; atividades antiinflamatória e de efeito vasodilatador; ação antialérgica; atividade contra o desenvolvimento de tumores, antihepatotóxica, antiulcerogênica; atuação antiplaquetária, bem como ações antimicrobianas e antivirais. Pesquisas recentes demonstraram que alguns flavonóides atuam na inibição da replicação viral do agente causador da Síndrome da Imunodeficiência Humana - HIV 9 .

Sabe-se que os flavonóides podem inibir vários estágios dos processos que estão diretamente relacionados com o início da aterosclerose, como ativação de leucócitos, adesão, agregação e secreção de plaquetas (Hladovec, 1986b), além de atividades hipolipidêmicas ${ }^{10}$ e aumento de atividades de receptores de $\mathrm{LDL}^{11}$.

Segundo Peterson e Dwyer ${ }^{5}$, os isoflavonóides (incolores) e flavonóis (amarelo pálido) são encontrados respectivamente, quase que exclusivamente, em legumes e em vegetais e frutas.

Lopes et al. $^{8}$ demonstraram que os flavonóides reduzem de forma significativa os níveis de colesterol e de triacilgliceróis, assim aumentando os valores de colesterol-HDL, destacando-se, inclusive, efeitos sinérgicos dos compostos flavonoídicos testados. Dessa forma, é fundamental o desenvolvimento de novas pesquisas sobre o potencial dos flavonóides no tratamento e na prevenção das hiperlipidemias, uma vez que a obtenção de novos resultados servirá de instrumento para a utilização desses produtos na prevenção de doenças cardiovasculares.

Os flavonóides são compostos fenólicos e têm sua estrutura baseada em 2-fenil-benzopirano (C6-C3-C6), sendo representados por várias classes, de acordo com o grau de oxidação do anel central ${ }^{12}$. Nas folhas, as flavonas e os flavonóis, por apresentarem sistemas mais conjugados, são considerados os principais pigmentos que absorvem luz $\mathrm{UV}^{13}$, além de serem os mais comuns ${ }^{14}$.

Para o estudo de flavonóides, optou-se pela análise quantitativa, em detrimento da análise qualitativa, por ser um tema pouco explorado tanto do ponto de vista quimiossistemático quanto ecológico, e que tem trazido inúmeras contribuições nestas áreas. $\mathrm{O}$ espectro de possibilidades em estudos de fatores ecológicos relativos à composição flavonoídica é imenso. Algumas pesquisas enfatizam diferenças quantitativas no perfil flavonoídico representam categorias de variações intraespecíficas tão importantes quanto as diferenças qualitativas ${ }^{7}$. 


\section{Objetivo}

Tendo em vista o baixo consumo de rabanete pela população goiana e seu baixo valor, selecionou-se este legume para estudo fitoquímico, visando incentivar o seu consumo na dieta diária.

\section{Materiais e Métodos}

Os espécimes de R. sativus foram coletados na cidade de Anápolis - Goiás. Em laboratório, as amostras foram lavadas para retirada de restos de poeira. Cada parte do rabanete foi separada e processada separadamente: as cascas foram retiradas e submetidas à secagem em estufa de ventilação forçada a $50^{\circ} \mathrm{C}$ pelo período de 24 horas; as folhas foram colocadas entre folhas de papel para secagem durante uma semana. O material seco foi triturado e a ele foi acrescido etanol $96 \%$ para obtenção de extrato bruto etanólico, sendo o mesmo evaporado em aparelho rotaevaporador e transferido para um béquer, permanecendo em dessecador até sua desidratação completa.

Baseada na técnica de MARCUCCI et al. ${ }^{15}$, foi feita a curva de calibração da solução padrão (rutina), diluída em $\mathrm{AlCl}_{3}$ 5\% (solubilizada em metanol 70\%), utilizando-se de espectrofotômetro UV e, posteriormente, as amostras (extratos brutos da folha, casca e bulbo) foram analisadas na concentração de $75 \mu \mathrm{g} / \mathrm{mL}$, sendo o comprimento de onda de $425 \mathrm{~nm}$.

\section{Resultados e Discussão}

Os flavonóides destacam-se, dentre os fitoquímicos, pela diversidade de ações no organismo humano, no que se refere a benefícios. Baseados em MARCUCCI et al. ${ }^{15}$, realizou-se a análise espectrofotométrica no comprimento de onda de $425 \mathrm{~nm}$, utilizando como solvente o $\mathrm{AlCl}_{3}$ $2 \%$ solubilizado em metanol $70 \%$. Segundo este autor, o AlCl3 permite uma melhor "visualização" dos flavonóides favorecendo sua identificação pela espectrofotometria UV. Após a análise dos padrões, foi obtido o coeficiente de correlação de 0,9908 e uma concentração de flavonóides de $4,5761 \mathrm{ppm}\left(0,46 \times 10^{-3} \%\right)$ no extrato bruto etanólico das folhas e 201,40 ppm (20,14\%) no extrato bruto etanólico da casca demonstrando sua presença significativa nas cascas da planta objeto de estudo.

De acordo com as exigências da legislação, cujo valor fixo é de, no mínimo, 5\% de flavonóides para comercialização de própolis ${ }^{16}$, evidencia-se que mesmo não sendo ainda estipulado um referencial para as folhas e cascas de rabanete, pode-se inferir que é um resultado significativo.

Nutricionistas estimam que o valor médio de ingestão de flavonóides é de 1 a $2 \mathrm{~g}$ por dia, sendo os flavonóis os predominantes ${ }^{17}$. Doses diárias recomendadas ainda não foram definidas.

Através destas análises, evidencia-se que a casca do rabanete e suas folhas devem ser utilizadas na alimentação diária por pessoas com índices de doenças cardiovasculares em sua família e como agente preventivo de tais anomalias por possuir ação antioxidante, minimizando a peroxidação lipídica e pelo seu efeito no combate aos radicais livres ${ }^{15}$.

\section{Conclusão}

O legume denominado popularmente rabanete, pode ser incluso no rol de alimentos funcionais, resultando em redução do risco de doenças e manutenção da saúde. Tendo em vista o seu baixo consumo, propõe-se sua inclusão na dieta diária.

Torna-se relevante a continuidade de estudos com este vegetal, buscando evidenciar quais os tipos de flavonóides estão presentes em maior quantidade, quais os grupos predominantes, buscando também avaliar a sua toxicidade, para que ensaios toxicológicos permitam o emprego de doses seguras dos flavonóides como fármacos.

\section{BIBLIOGRAFIA}

1. Borges, VC. Alimentos funcionais: prebióticos, probióticos, fitoquímicos e simbióticos. In: Waitzberg DL. Nutrição Enteral e Parenteral na Prática Clínica, Atheneu: São Paulo, 2001.

2. Anjo, D.F.C. J. Vasc. Br. 2004; 3(2); 145.

3. Ada, American Dietetic Association; Position of the American Dietetic Association: functional foods. 1999; 10: 1278.

4. German, B; Dillard, C. J.; J. Sci. Food Agric. 2000; $80 ; 1744$. 
5. Peterson, J.; Dwyer, J.; Nutrition Research, 1995, 18(12);

6. Hillis, W.E.; Swain, T.; J. Sci. Food Agric. 1959, 10; 135.

7. Bohm, B.A.; Bot. Rev., 1987, 53, 197.

8. Lopes, R.M.; Oliveira, T.T.; Nagem, T.J.; Pinto, A.S.; . Revista Biotecnologia, 2000, 17, 18.

9. Lim, M.; Anderson, H.; Flavin, M.T.; Pai, Y.S. Journal Natural Products, 1997, 60, 884.

10. Lin, B.B.; Chen, H.L; Huang, P.C. Nutr. Rep. Int. 1986, 34, 821 .

11. Kirk, E.A.; Sutherland, P.; Wang, S.A.; Shait, A., Leboeuf, R.C.; J. Nutr. 1988, 12, 954.

12. Harborne, J.B; Flavonoids. In Phytochemistry VII. (L.P. Miller, ed.). Van Nostrand Reinhold Company: New York, 1973.

13. Harborne, J.B.; Biochem. Syst. Ecol. 1977, 5, 7.

14. Pietta, P.G.; Mauri, P.L.; Manera, E.; Ceva, P.L.; Rava, A. 1989. Chromatographia. 1989, 27, 509.

15. Marcucci, M. C.; Woisky, R. G.; Salatino, A. Uso de cloreto de alumínio na quantificação de flavonóides em amostras de própolis. (Disponível em: <http:// www.bichoonline.com.br/artigos/apa0014.htm> Acesso em 02/02/2009.

16. Brasil. Ministério da Agricultura. Anexo VI Regulamento técnico para fixação de identificação e qualidade de própolis. Brasília, DF. Ministério da Agricultura, 2002.

17. Silva, M. B. S. Flavonóides com capacidade antioxidante. Artigo de revisão, Faculdade de Ciências e Tecnologia, Universidade Nova de Lisboa, 2005.

\section{Rejane D. P. Mota*1, Talita L. C. de Castro', Tatiana de Oliveira Zuppa² \& Eliane V. Rosa'}

\footnotetext{
${ }^{1}$ FATEC Senai Roberto Mange

${ }^{2}$ Universidade Estadual de Goiás - UEG, Unidade Universitária de Ciências Exatas e Tecnológicas, 2008.

*e-mail: rejane.senai@sistemafieg.org.br
} 